The recommended first aid is to remove powder from the mouth, give water or milk, observe for foam inhalation, and do not give acid substances.

The manufacturers state that they know of no previous cases despite the global distribution of this product.

I thank the Aboriginal health workers and Sister Rachel Jordan for their help, and J Hole, Lever and Kitchen, Sydney, for the technical information.

${ }^{1}$ Eastwell HD. Petrol inhalation in Aboriginal towns. Med $\mathcal{F}$ Aust 1979;ii 222-4.

2 Bateson EM. Clay eating by Aboriginals of the Northern Territory. Med $\mathcal{F}$ Aust $1978 ; 1$ special supplement No I:1-3.

(Accepted 8 December 1982)

East Arnhem Region, NT 5797, Australia

DAVID S WATSON, MB, FRACGP, regional medical officer

\section{Intraperitoneal hydrocortisone in eosinophilic peritonitis associated with continuous ambulatory peritoneal dialysis}

Eosinophilic peritonitis occurs in a small but notable number of cases of culture-negative peritonitis in patients treated with continuous ambulatory peritoneal dialysis. The diagnostic feature is a high eosinophil count in the effluent dialysate which is often associated with peripheral eosinophilia. ${ }^{1-3}$ The incidence of this condition has risen recently as differential white cell counts of the dialysate are routinely performed in investigating culture-negative peritonitis in patients undergoing continuous ambulatory peritoneal dialysis. We report such a case which responded promptly to treatment with intraperitoneal hydrocortisone.

\section{Case report}

A 57 year old woman with chronic renal failure secondary to polycystic kidney disease began treatment with continuous ambulatory peritonea dialysis. She also had chronic obstructive airways disease and allergy to house dust and camel hair, for which she was treated with salbutamol, ipratropium inhalers, and vitamin supplements. Two days after a Tenckhoff peritoneal catheter had been inserted and one day after she had begun dialysis she developed peritonitis with a turbid effluent dialysate, low grade pyrexia, and mild abdominal tenderness. Repeated microbiological cultures-for anaerobes, tubercle bacilli, and fungi-were all negative despite a consistently raised dialysate white cell count $>1 \times 10^{9} / 1\left(>1000\right.$ cells $\left./ \mathrm{mm}^{3}\right)$. The initial symptoms persisted and she developed hypoalbuminaemia, oedema, and postural hypotension. Several courses of intraperitoneal antibiotics, including cephalothin, gentamicin, and vancomycin, were ineffective, and intravenous infusions of albumin deficient in sodium were required on several occasions.

One month after the onset of peritonitis a differential white cell count on the effluent dialysate showed $80 \%$ eosinophils. Peripheral eosinophilia ( $>40 \%$ eosinophils) was also present. On the basis that the peritonitis was allergic in origin all drugs, antibiotics, and disinfectants containing iodine were stopped and the brand of dialysis fluid and tubing changed. Despite an initial improvement in the cell count a relapse occurred four weeks later. Intraperitoneal hydrocortisone was started; the initial dose of $200 \mathrm{mg}$ daily was rapidly decreased to $40 \mathrm{mg}$ daily. The peritonitis completely resolved and within a week the dialysate total white cell count fell below $0.005 \times 10^{9} / 1$ $\left(5 / \mathrm{mm}^{3}\right)$ and contained no eosinophils. Protein losses in the dialysate decreased appreciably and the serum albumin concentration rose without further albumin infusions. After nine weeks treatment with hydrocortisone was stopped, but a relapse occurred within a week. Hydrocortisone was reinstituted and complete resolution occurred both clinically and cytologically (figure).

\section{Comment}

Though eosinophilic peritonitis has occurred in association with intermittent peritoneal dialysis, ${ }^{4}$ it has only recently been reported in patients undergoing continuous ambulatory peritoneal dialysis. ${ }^{1-3}$ As in our patient the peritonitis developed shortly after insertion of the peritoneal catheter, usually within two weeks. In these reports symptoms were relatively mild or even absent, apart from a turbid

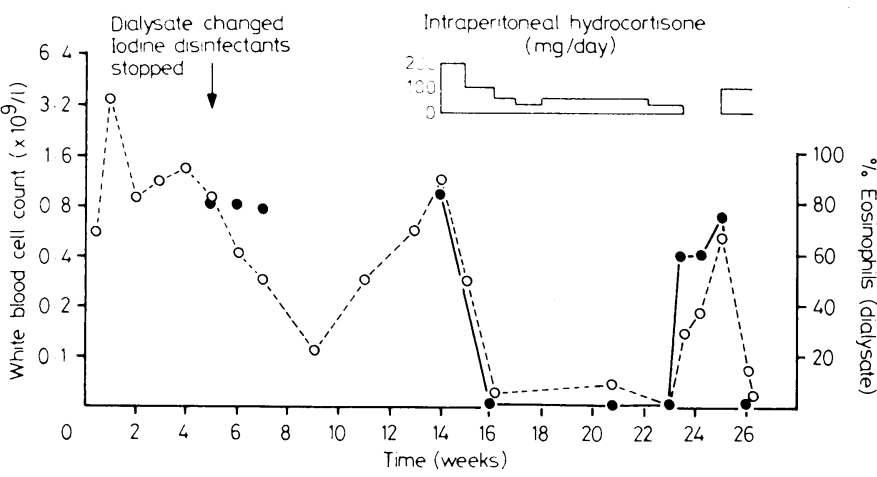

Serial white blood cell counts in peritoneal dialysis fluid: $(\ldots \ldots$, , white blood cells; $0, \%$ eosinophils.

effluent dialysate. Antibiotic treatment was ineffective and the diagnosis made only after repeated negative cultures and differential white cell counts of the effluent dialysate. Though most cases resolved spontaneously within two months, in some cases of intermittent peritoneal dialysis they took up to 24 months to resolve. ${ }^{4}$

Our patient appeared to have a particularly severe peritonea eosinophilic reaction. Though changing the brand of dialysate and the antiseptics produced a partial response, the dialysate white cell coun did not return to normal values. Only treatment with intraperitoneal hydrocortisone produced a normal count on two occasions.

The cause of eosinophilic peritonitis is still unclear, though peritoneal hypersensitivity to allergens-such as povidone-iodine, talc, particulate matter in the dialysate, plasticisers used in the manufacture of tubing, peritoneal catheters, or even blood from retrograde menstruation-may be responsible. ${ }^{1-5}$ Our patient had a history of atopy which may have contributed to her eosinophilic response to an unknown allergen.

Since patients undergoing continuous ambulatory peritoneal dialysis may develop culture-negative peritonitis, particularly soon after insertion of a peritoneal catheter, differential white cell counts of the effluent dialysate should be performed at an early stage. Antibiotic treatment is ineffective. In cases in which the clinical condition deteriorates and dialysis needs to be continued intraperitoneal hydrocortisone should be given in low doses after possible allergens have been carefully looked for.

${ }^{1}$ Noph KD, Sorkin MI, Prowant BF, et al. Symptomatic eosinophilic peritonitis in CAPD. Dialysis and Transplantation 1982;11:309-13.

2 Gokal R, Ramos JM, Ward MK, Kerr DNS. "Eosinophilic" peritonitis in CAPD. Clin Nephrol $1981 ; \mathbf{1 5}: 328-30$.

${ }^{3}$ Spinowitz BS, Golden RA, Rascoff JH, Charytan C. Eosinophilic peritonitis. In : Gahl GM, ed. Advances in peritoneal dialysis. Amsterdam Excerpta Medica, $1981: 276-80$.

+ Humayun HM, Ing TS, Daugirdas JT, et al. Peritoneal fluid eosinophilia in patients undergoing maintenance peritoneal dialysis. Arch Intern Med $1981 ; 141: 1172-3$

${ }^{5}$ Lasker N, Burke JF, Patchefsky A, et al. Peritoneal reactions to particulate matter in peritoneal dialysis solutions. Trans Am Soc Artif Intern Organ $1975 ; 21$ : $342-5$

(Accepted 24 November 1982)

Departments of Medicine and Bacteriology, Royal Infirmary Glasgow G4 OSF

A C T LEUNG, MRCP, registrar

G ORANGE, $M B$, registrar

I S HENDERSON, MRCP, senior registrar

THYME is a noble strengthener of the lungs, as notable a one as grows ; neither is there scarce a better remedy growing for that disease in children which they commonly call the Chin-cough, than it is. It purges the body of phlegm, and is an excellent remedy for shortness of breath. It kills worms in the belly, and being a notable herb of Venus, provokes the terms, gives safe and speedy delivery to women in travail, and brings away the after birth. It is so harmless you need not fear the use of it. An ointment made of it takes away hot swellings and warts, helps the sciatica and dullness of sight, and takes away pains and hardness of the spleen. Tis excellent for those that are troubled with the gout. It eases pains in the loins and hips. The herb taken any way inwardly, comforts the stomach much, and expels wind. (Nicholas Culpeper (1616-54) The Complete Herbal, 1850.) 